\title{
The morphology, D.C Conductivity and Activation Energy of CdS:Zn Films Fabricated by chemical spray pyrolysis
}

\author{
Received : 7/12/2017 \\ Accepted : 18/1/2018 \\ Ihsan R.Ghanim , Mohammed R.Kahlil , Nawras T. Shihab \\ University of Babylon, College of Education for Pure Science, Iraq \\ E-mail: mohmaster11@gmail.com
}

\begin{abstract}
:
Znic doped CdS thin films with different volume percentage (3,6 and 9) were fabricated by spray pyrolysis technique at a substrate temperature $400^{\circ} \mathrm{C}$. The thickness deposited film were $80 \mathrm{~nm}$. Surface morphology test by AFM indicate that the surface of films is smooth and it showed an decrease in (RMS) values with increasing Zinc ratio. It has been making D.C conductivity measurements for all films. The results showed that the conductivity increased with increasing $\mathrm{Vol} . \% \mathrm{Zn}$, as well as the results showed that all films have two activation energy and this energy increase with increasing Vol.\%Zn.
\end{abstract}

Keywords: CdS:Zn, Thin Film, spray pyrolysis technique

\section{Introduction :}

Thin Film technology is a layer or several layers of atoms for a certain substance whose thickness ranges between $10 \mathrm{~nm}$ and less than $1 \mu \mathrm{m}$ [1]. Cadmium sulfide $\mathrm{CdS}$ one of the most important II-VI group semiconductors belonging to the family Chalcogenide, which has two crystal structures, zinc blende [2]or hexagonal closed Packed type wurtzite phases [3]. The interest in thin films raised from the wide range of use and application in electronic equipments and devices. These films have been used in various fields such as of manufacturing (p-n) junctions, rectifiers, mirrors with two types ordinary and thermally, reflected and antireflected coating, photograph, integrated circuits, and optical communications as light emitting diodes, detectors solar cells, .., etc. This leads to study of electronic properties of thin films [4],[5] .

\section{Materials and method:}

$\mathrm{CdS}$ and CdS:Zn thin films were prepared on to glass substrate at $400^{\circ} \mathrm{C}$ by chemical spray pyrolysis with different volume percentage (3,6, and9) of $\mathrm{Zn}$. The films were prepared by mixing aqueous cadmium nitrate-4-hydral solution $\mathrm{Cd}\left(\mathrm{NO}_{3}\right)_{2} \cdot 4 \mathrm{H}_{2} \mathrm{O}$ with aqueous thiourea solution $\mathrm{CS}\left(\mathrm{NH}_{2}\right)_{2}$. Zinc doped $\mathrm{CdS}$ films were deposited by adding Aqueous zinc chloride solution as a dopant source to the solution. The spray rate was optimized to 3 $\mathrm{ml} / \mathrm{min}$ through the nozzle to ensures a uniform film thickness.

$\mathrm{Cd}\left(\mathrm{NO}_{3}\right)_{2} \cdot 4 \mathrm{H}_{2} \mathrm{O}+\mathrm{CS}\left(\mathrm{NH}_{2}\right)_{2}-\mathrm{CdS}+\mathrm{CO}_{2}$ $+6 \mathrm{H}_{2} \mathrm{O}+2 \mathrm{~N}_{2} \mathrm{O}$

The thicknes of our films were measured using BLK-CXR-SR-25, also by weight method. Atomic force microscopy AFM (AA3000 SPM) was used to study the surface morphology of the films. The electrical conductivity $\left(\sigma_{\text {d.c }}\right)$ has been measured as a function of temperature in the range $(20-200)$ ${ }^{\circ} \mathrm{C}$ for each $10 \mathrm{~min}$ by using the electrical circuit shown in Figure (1). 
The electrical resistivity $\left(\rho_{\text {D.C }}\right)$ of the films is calculated by using the equation below [6]:

$$
\rho_{\text {D.C }}=\mathrm{R} \frac{\mathrm{b} \times \mathrm{t}}{\mathrm{L}}
$$

Where: $\mathrm{R}$ is the sample resistance, $\mathrm{b}$ is the width of electrodes, $t$ the film thickness, and $\mathrm{L}$ the distance between two electrodes. The electrical conductivity $\left(\sigma_{\text {d.c }}\right)$ equal to the inverse value of the electrical resistivity. The activation energies ( $E_{a}$ )could be calculated
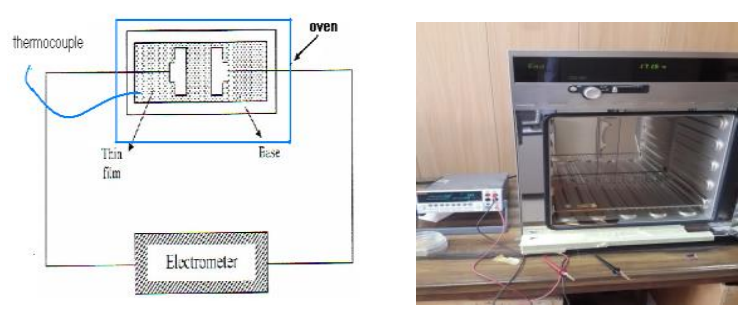

Figure (1): Set-up and photograph illustrates the D.C electrical conductivity.

\section{Results and Discussion:}

The Surface morphology and electrical properties of $\mathrm{CdS}: \mathrm{Zn}$ thin films were investigated as follows:

\section{Surface morphology of the films:}

The optical behavior of single and multiple homogeneous coatings is well understood. Therefore, checking it by morphologic study is
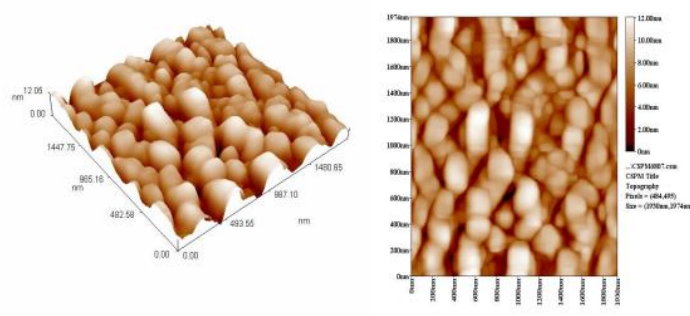

$\mathbf{a}$

b from the plot of $\ln \sigma$ versus 1000/T according to equation below [7]:

$$
\ln \sigma_{\text {D.C }}=\ln \sigma_{\mathrm{o}}-\frac{\Delta \mathrm{E}_{\mathrm{a}}}{\mathrm{k}_{\mathrm{B}} \mathrm{T}}
$$

Since : $\ln \sigma_{\mathrm{o}}-\frac{\Delta \mathrm{E}_{\mathrm{a}}}{\mathrm{k}_{\mathrm{B}}} \quad$ is numerical constant .

a good proof for homogeneity. The $2 \mathrm{D}$ and $3 \mathrm{D}$ surface morphologies of the CdS and CdS; Zn thin films was performed using atomic force microscopy as shown in Figures (2),(3),(4) and (5). From there Figures, it can be noticed that a root mean square (RMS) roughness ranged from 0.941 to $2.4 \mathrm{~nm}$, and a maximum peak to peak height, $\mathrm{Sz}$ (ten point height) ranged from 2.12 to $5.28 \mathrm{~nm}$, which denotes that the surface of films are highly smooth, as shown in the Table (1).

Figure (2): AFM surface morphology of $\mathrm{CdS}$ thin film prepared at thickness $80 \mathrm{~nm}$.

a) 2-D, and b) 3-D. 
$\mathbf{a}$

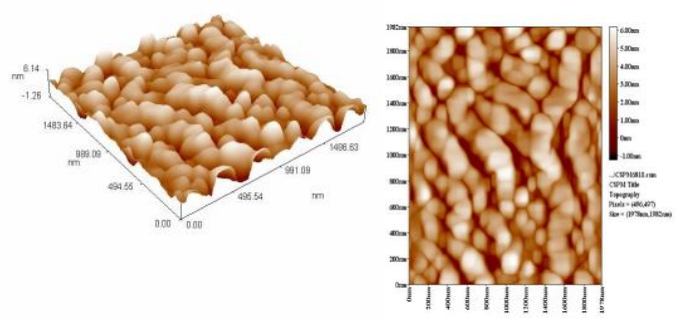

Figure (3): AFM surface morphology of CdS: $3 \% \mathrm{Zn}$ thin film prepared at thickness 80nm. a) 2-D, and b) 3-D.

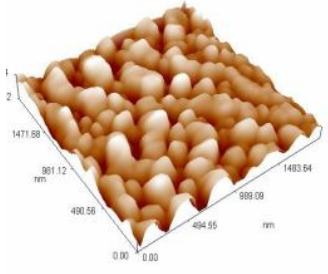

a

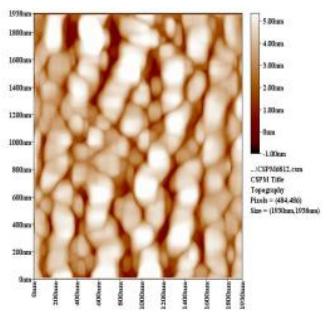

b

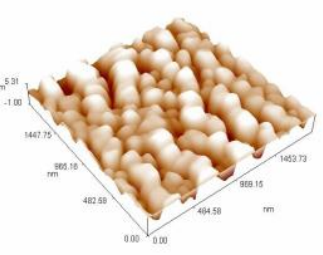

$\mathbf{a}$

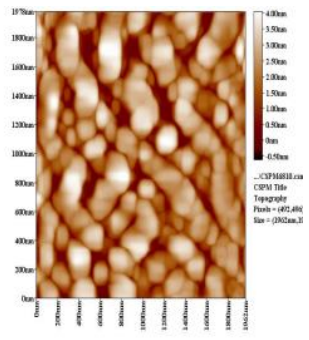

b
Figure (4): AFM surface morphology of CdS: $6 \% \mathrm{Zn}$ thin film prepared at thickness 80nm. a) 2-D, and b) 3-D
Figure (5): AFM surface morphology of CdS: $9 \% \mathrm{Zn}$ thin film prepared at thickness $80 \mathrm{~nm}$. a) 2-D, and b) 3-D

\begin{tabular}{|c|c|c|c|c|c|}
\hline sample & $\begin{array}{c}\text { RMS } \\
(\mathrm{nm})\end{array}$ & $\begin{array}{c}\text { Roughness } \\
(\mathrm{nm})\end{array}$ & $\begin{array}{c}\text { Ten point } \\
\text { height }(\mathrm{nm})\end{array}$ & $\begin{array}{c}\text { Surface thickness } \\
(\mathrm{nm})\end{array}$ & $\begin{array}{c}\text { Average Diameter } \\
(\mathrm{nm})\end{array}$ \\
\hline 0 & 2.4 & 1.95 & 5.28 & 12.05 & 99.11 \\
\hline $3 \% \mathrm{Zn}$ & 1.37 & 1.11 & 3.81 & 6.14 & 86.70 \\
\hline $6 \% \mathrm{Zn}$ & 1.22 & 0.991 & 3.2 & 5.31 & 71.41 \\
\hline $9 \% \mathrm{Zn}$ & 0.941 & 0.767 & 2.12 & 4.04 & 71.13 \\
\hline
\end{tabular}

Table (1) Morphological characteristics of CdS:Zn.

The D.C conductivity and activation energy: 
The electrical conductivity $\sigma_{\text {d.c }}$ depends upon several factors such as the preparation technique, the annealing temperature and the measurement conditions .Figure (6) shows the variation of $\sigma_{\text {d.c }}$ versus the absolute temperature (T).From this figure it can be notice that $\sigma_{\text {d.c }}$ for $\mathrm{CdS}$ increased with temperature, this seems to be a normal behavior as one of semiconductor properties, due to the increasing carrier concentration with temperature .Also when CdS doping different concentration of $\mathrm{Zn}$, the $\sigma_{\mathrm{d} . \mathrm{C}}$ was increased with increasing $\mathrm{T}$. this resalts may be attribute to the decrement of the surface roughness of films, The activation energy (Ea) obtained for

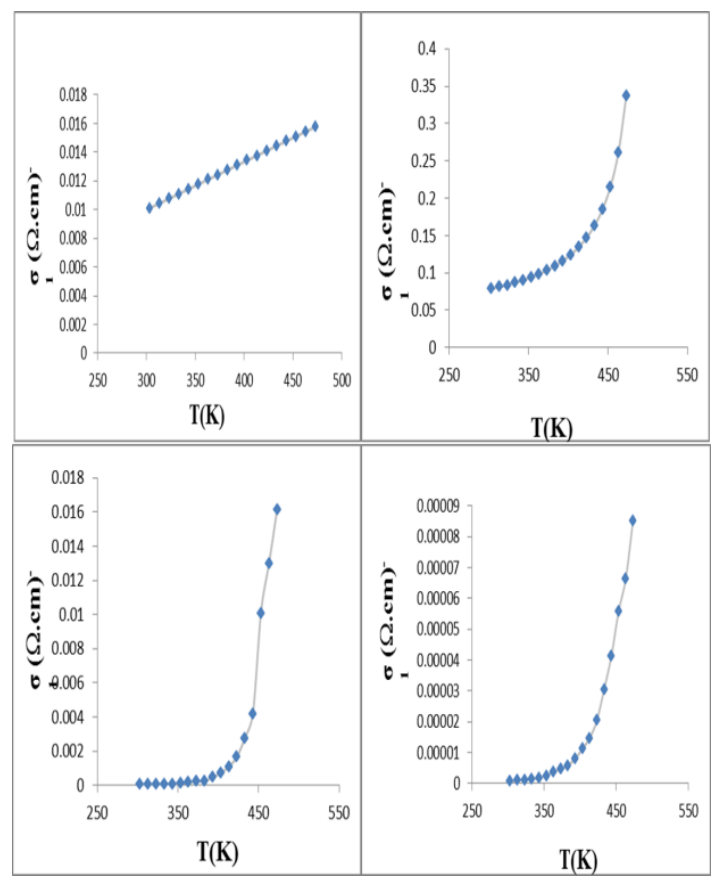

Figure(6): Variation of $\sigma_{D . C}$ versus temperature for $\mathrm{CdS}$ thin films at different Vol.\% of Zn. these films is given in the Table(2), which calculated from the slope of $\ln \sigma \quad$ vs. 1000/T according to eq.(2) which shown in Figure(7).From this figure the films having two activation energy depend on doping value. This means there are two mechanisms for conductivity. The activation energy in the low temperature depends on the ionization impurity and at high temperature depends on the generation of electron-hole pairs. Table(2) shows that the value of $\left(\mathrm{Ea}_{1}\right)$ is smaller than values of $\left(\mathrm{Ea}_{2}\right)$. This indicates that the conductivity depends on the temperature where $\sigma \alpha \mathrm{T}^{3 / 2}[8]$.

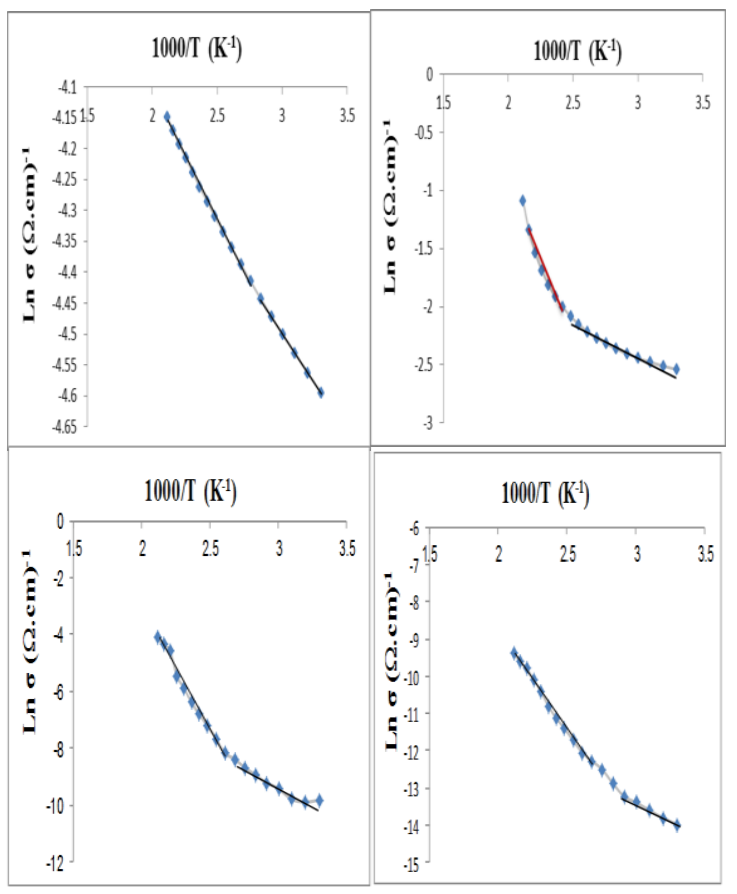

Figure (7):Lno versus 1000/T for CdS thin films at different Vol.\% of Zn.

\begin{tabular}{|c|c|c|c|c|}
\hline Sample & $\begin{array}{c}\mathrm{Ea}_{1} \\
(\mathrm{eV})\end{array}$ & $\begin{array}{c}\text { Temp.Range } \\
(\mathrm{K})\end{array}$ & $\begin{array}{c}\mathrm{Ea}_{2} \\
(\mathrm{eV})\end{array}$ & $\begin{array}{c}\text { Temp.Range } \\
(\mathrm{K})\end{array}$ \\
\hline 0 & 0.032500307 & $303-353$ & 0.13775835 & $363-473$ \\
\hline $3 \% \mathrm{Zn}$ & 0.03745 & $323-413$ & 0.152517479 & $423-473$ \\
\hline
\end{tabular}




\begin{tabular}{|c|c|c|c|c|}
\hline $6 \% \mathrm{Zn}$ & 0.05878 & $313-383$ & 0.236953921 & $393-473$ \\
\hline $9 \% \mathrm{Zn}$ & 0.1321 & $303-333$ & 0.33001688 & $353-473$ \\
\hline
\end{tabular}

Table (2): D.C. conductivity parameters for CdS thin films at different Vol.\% of Zn.

\section{Conclusion:}

A homogenous CdS and CdS:Zn thin films have been successfully prepared by chemical spray pyrolysis. The morphological studies revealed that the films are highly smooth. D.C measurements indicate that the conductivity $\left(\sigma_{\text {d.c }}\right)$ of all films are increased with the

\section{References:}

1. K.L.Chopra, 1983."Thin Film development of automated liquid Devices Application", Plenum flow deposition method for thin Press, New York,

2. M.A.Metzger, (Jul/Aug Research, Vol. 3, pp.438-447. 1995).Compound, semiconductors 8 . $, 1,26$

3. M.S. Tyagi,1991, Introduction to semiconductor materials, John Wiley \&Sons, New York.

4. L. Eckortova,1977, "Physics of Thin Films ", plenum press.

5. A.H. Anderson,1982" Solar cell" (5), PP.234-268.

6. M.A. Islam ,M.S. Hossain, 2013" Comparison of Structural and Optical Properties of CdS Thin Films Grown by CSVT, CBD and Sputtering Techniques",Solar Energy Research Institute, The National University of Malaysia, Vol .33, pp. 203-213.

7. S. Sriram, A. Balu and A. Thayumanavan, 2011 " Design and increasing temperature, as a result of a decrement of surface roughness and it was found that the films having two activation energy $\left(\mathrm{Ea}_{1}\right.$ and $\left.\mathrm{Ea}_{2}\right)$ depend on doping value .The value of $\mathrm{Ea}_{1}$ is always less than that of $\mathrm{Ea}_{2}$. film formation", Applied Science and Semiconductors", McGraw-Hill, Landon. 